\title{
Regional Myo-Inositol, Creatine, and Choline Levels Are Higher at Older Age and Scale Negatively with Visuospatial Working Memory: A Cross-Sectional Proton MR Spectroscopy Study at 7 Tesla on Normal Cognitive Ageing
}

\author{
${ }^{\circledR}$ Anna Lind, ${ }^{1}{ }^{\circledR}$ Carl-Johan Boraxbekk, ${ }^{1,2,3}{ }^{\circledR}$ Esben Thade Petersen, ${ }^{1,4}{ }^{\circledR}$ Olaf Bjarne Paulson, ${ }^{5,6}$ \\ ${ }^{-}$Hartwig Roman Siebner, ${ }^{1,6,7}$ and ${ }^{(1)}$ Anouk Marsman ${ }^{1}$ \\ ${ }^{1}$ Danish Research Centre for Magnetic Resonance, Centre for Functional and Diagnostic Imaging and Research, Copenhagen University Hospital Hvidovre, \\ Hvidovre, 2650, Denmark, ${ }^{2}$ Department of Radiation Sciences, Umeå University, Umeå, 90187, Sweden, ${ }^{3}$ Institute of Sports Medicine Copenhagen, \\ Copenhagen University Hospital Bispebjerg, Copenhagen, 2400, Denmark, ${ }^{4}$ Center for Magnetic Resonance, Department of Health Technology, Technical \\ University of Denmark, Kongens Lyngby, 2800, Denmark, ${ }^{5}$ Neurobiology Research Unit, Department of Neurology, Copenhagen University Hospital \\ Rigshospitalet, Copenhagen, 2100, Denmark, ${ }^{6}$ Department of Clinical Medicine, Faculty of Health and Medical Sciences, University of Copenhagen, \\ Copenhagen, 2200, Denmark, and ${ }^{7}$ Department of Neurology, Copenhagen University Hospital Bispebjerg, Copenhagen, 2400, Denmark
}

Proton MR spectroscopy ( $\left.{ }^{1} \mathrm{H}-\mathrm{MRS}\right)$ has been used to assess regional neurochemical brain changes during normal ageing, but results have varied. Exploiting the increased sensitivity at ultra-high field, we performed ${ }^{1} \mathrm{H}$-MRS in 60 healthy human volunteers to asses age-related differences in metabolite levels and their relation to cognitive ageing. Sex was balanced, and participants were assigned to a younger, middle, and older group according to their age, ranging from 18 to 79 years. They underwent $7 \mathrm{~T}{ }^{1} \mathrm{H}-\mathrm{MRS}$ of the ACC, DLPFC, hippocampus, and thalamus and performed a visuospatial working memory task outside the scanner. A multivariate ANCOVA revealed a significant overall effect of age group on metabolite levels in all regions. Higher levels in the middle than the younger group were observed for myo-inositol (mIns) in DLPFC and hippocampus and total choline (tCho) in ACC. Higher levels in the older than the younger group were observed for mIns in hippocampus and thalamus, total creatine (tCr) and tCho in ACC and hippocampus; lower levels of glutamate (Glu) were observed in DLPFC. Higher levels in the older than the middle group were observed for mIns in hippocampus, $\mathrm{tCr}$ in ACC and hippocampus, tCho in hippocampus, and total $N$-acetyl aspartate (tNAA) in hippocampus. Working memory performance correlated negatively with $\mathrm{tCr}$ and tCho levels in ACC and mIns levels in hippocampus and thalamus, but not with tNAA or glutamate levels. As NAA and Glu are commonly regarded to reflect neuronal health and function and concentrations of $\mathrm{mIns}, \mathrm{tCr}$, and tCho are higher in glia than neurons, the findings of this study suggest a potential in vivo connection between cognitive ageing and higher regional levels of glia-related metabolites.

Key words: ACC; ageing; cognition; hippocampus; neurochemistry; thalamus

Significance Statement

Neurochemical ageing is an integral component of age-related cognitive decline. Proton MR spectroscopy $\left({ }^{1} \mathrm{H}-\mathrm{MRS}\right)$ studies of in vivo neurochemical changes across the lifespan have, however, yielded inconclusive results. ${ }^{1} \mathrm{H}$-MRS at ultra-high field strength can potentially improve the consistency of findings. Using $7 \mathrm{~T}^{1} \mathrm{H}$-MRS, we assessed levels of mIns, $\mathrm{tCr}$, and tCho (glia-related metabolites) and tNAA and Glu (neuron-related metabolites) in ACC, DLPFC, hippocampus, and thalamus. We found higher levels of gliarelated metabolites in all brain regions in older individuals. Working memory performance correlated negatively with regional levels of glia-related metabolites. This study is the first to investigate normal ageing in these brain regions using $7 \mathrm{~T}^{\mathrm{l}} \mathrm{H}-\mathrm{MRS}$ and findings indicate that glia-related metabolites could be valuable in cognitive ageing studies.

Received Dec. 4, 2019; revised Aug. 12, 2020; accepted Sep. 6, 2020.

Author contributions: A.L., C.-J.B., E.T.P., H.R.S., and A.M. designed research; A.L. performed research; A.L., C.-J.B., E.T.P., H.R.S., and A.M. analyzed data; A.L. wrote the first draft of the paper; A.L., C.-J.B., E.T.P., O.B.P., H.R.S., and A.M. edited the paper; A.L., C.-J.B., and A.M. wrote the paper.

H.R.S. has received honoraria as speaker from Sanofi Genzyme, Denmark, and Novartis, Denmark, as consultant from Sanofi Genzyme, Denmark, and as senior editor (Neurolmage) from Elsevier Publishers, Amsterdam, The Netherlands. He has received royalties as book editor from Springer Publishers, Stuttgart, Germany. The remaining authors declare no competing financial interests.
This work was supported by Danish Agency for Science, Technology and Innovation Grant 0601-01370B, Lundbeck Foundation Grant R118-A11719, and John and Birthe Meyer Foundation. H.R.S. holds a 5 year professorship in precision medicine at the Faculty of Health Sciences and Medicine, University of Copenhagen, which is sponsored by Lundbeck Foundation Grant R186-2015-2138.

Correspondence should be addressed to Anouk Marsman at anoukm@drcmr.dk.

https://doi.org/10.1523/JNEUROSCI.2883-19.2020

Copyright $\odot 2020$ the authors 


\section{Introduction}

Describing normal human ageing is vital for understanding what distinguishes both successful and pathologic ageing. Normal ageing involves cognitive decline related to widespread neurochemical alterations (Driscoll et al., 2003). These alterations have been studied noninvasively and in vivo using proton MR spectroscopy $\left({ }^{1} \mathrm{H}-\mathrm{MRS}\right)$; however, the results have been highly variable (for review, see Haga et al., 2009; Cichocka and Bereś, 2018; Cleeland et al., 2019).

The most commonly investigated brain metabolites in ${ }^{1} \mathrm{H}$ MRS ageing studies are myo-inositol (mIns), total creatine (tCr), total choline (tCho), total N-acetylaspartate (tNAA), and glutamate (Glu) (Cichocka and Bereś, 2018). Although results from ${ }^{1} \mathrm{H}-\mathrm{MRS}$ ageing studies have varied, the most consistent results indicate that mIns, tCr, and tCho levels increase with age, whereas tNAA and Glu levels decrease (Cleeland et al., 2019). Because of the variation in results, this ageing pattern is, however, not conclusively established.

One reason for the previous variation in results could be that the neurochemical changes during ageing are highly region-dependent (Eylers et al., 2016). In ageing-sensitive regions, such as PFC and hippocampus, age effects on metabolite levels are frequently observed, although the specific metabolites and the direction of the effect vary (Schubert et al., 2004; Chiu et al., 2014; Ding et al., 2016; Sporn et al., 2019). In other regions, such as thalamus, age-related effects on metabolite levels are rarely observed (Gruber et al., 2008; Yang et al., 2015; Eylers et al., 2016) . These previous results may also depend on tissue composition in the ROI, as the effect of ageing on metabolite levels has been observed to differ depending on relative gray matter (GM) and white matter (WM) fractions (Ding et al., 2016). In the present study, we included one ROI in the anterior cingulate cortex (ACC), which primarily contained GM, one ROI in the DLPFC, which primarily contained WM, and one ROI in the hippocampus. Additionally, an ROI in the thalamus was chosen as this region is highly connected to the PFC and the hippocampus, while not being considered particularly ageing-sensitive.

There are a number of additional potential reasons for the variability of the results, such as the included age spans and sample sizes (Cichocka and Bereś, 2018). Further, many studies quantify metabolite levels by calculating the ratio to tCr. As tCr is indicated to change with age, this complicates interpretation of the results (Cleeland et al., 2019). Moreover, the distribution of $\mathrm{GM}, \mathrm{WM}$, and CSF within a given ${ }^{1} \mathrm{H}$-MRS voxel depends on each individual's anatomy, and the extent to which this is corrected for may influence the results. Last, variability of results could arise from differences in field strength (Tkác et al., 2001; Terpstra et al., 2016) and parameters, such as TR and TE (Sporn et al., 2019). Developments in ${ }^{1} \mathrm{H}$-MRS hardware and best practice could, thus, increase the consistency and interpretability of the results.

The overall aim of this study was to investigate regional brain metabolite differences across three age groups of normal individuals using $7 \mathrm{~T}{ }^{1} \mathrm{H}-\mathrm{MRS}$ and to relate the differences in metabolite levels to cognitive ageing. The primary hypothesis was that the metabolite levels would differ across age groups in a region-dependent manner. More specifically, it was predicted that, in the regions proposed to be more ageing-sensitive, namely, ACC, DLPFC, and hippocampus, older age groups would show higher levels of mIns, tCr, and tCho and lower levels of tNAA and Glu. In thalamus, no differences were expected. The secondary hypothesis was that ageing-sensitive metabolites would be associated with cognitive ageing. Visuospatial working memory
Table 1. Demographics ${ }^{a}$

\begin{tabular}{lccc}
\hline Variable & Younger & Middle & Older \\
\hline No. of participants (women) & $20(10)$ & $20(10)$ & $19(9)$ \\
Age (yr) & $22.6 \pm 2.37^{* *}$ & $44.1 \pm 3.64^{* *}$ & $72.5 \pm 2.78^{* *}$ \\
BMl & $22.6 \pm 1.72^{* *}$ & $26.6 \pm 4.28^{*}$ & $26.6 \pm 3.45^{*}$ \\
Education (yr) & $15.2 \pm 2.03$ & $16.0 \pm 2.82$ & $15.1 \pm 2.64$ \\
\hline
\end{tabular}

${ }^{a}$ Data are mean \pm SD.

Age groups that are pairwise significantly different $(p<0.05)$ : *different from one other group; ${ }^{* *}$ different from both other groups.

(vsWM) was chosen to exemplify cognitive ageing based on the literature showing how this function is sensitive to ageing and depends on the ROIs in this study (Owen et al., 1996; Brockmole and Logie, 2013; Goldstone et al., 2018).

\section{Materials and Methods \\ Participants}

Participants were recruited through online advertisements on a national Danish participant recruitment page (www.forsoegsperson.dk) and through an advertisement in a local newspaper. Sixty participants in total were included, 20 in each of the three age groups: 18-26years old (younger), 39-50 years old (middle), and 69-79 years old (older). The three age groups were chosen to sample brain metabolite levels at early, middle, and later points of adult life with a reasonable range of ages within each group. Inclusion happened in parallel for all three groups. Exclusion criteria were as follows: MR contraindications, major psychiatric or neurologic history, history of drug or alcohol abuse, participation in medical drug testing within 6 months of the experiment, smoking within 3 months of the experiment, infectious disease within 3 weeks of the experiment, morbid obesity, pregnancy, and insufficient understanding of Danish. One participant from the older group was excluded because of an unexpected pathologic finding (Table 1).

Participants fasted but were allowed to drink water from 22:00 h the day before the experiment and until the experiment was over. Although it is not clear whether having breakfast is beneficial for working memory performance compared with not having breakfast, breakfast composition may affect working memory performance (Galioto and Spitznagel, 2016). To avoid any confounding effect of different nutritional intake across participants, we required the participants to fast overnight. All participants underwent MR scanning between 9:00 h and 11:00 h immediately followed by cognitive testing. Participants were informed orally and in writing about the experiment. They provided written consent before the experiment. After the experiment, all participants were reimbursed for their time spent participating. The study was approved by the Regional Committee on Health Research Ethics from the Capital Region in Denmark and was performed in accordance with the declaration of Helsinki (amendment of Fortaleza, 2013).

\section{MR acquisition}

A Philips 7T whole body MR scanner (Philips) was used in combination with a dual transmit coil and a 32-channel receive head coil (Nova Medical). The MR sequences described in this study were part of a larger scan protocol; total scan time per participant was $90 \mathrm{~min}$ at maximum.

A $\mathrm{T}_{1}$-weighted MPRAGE sequence (slices $=380$, slice thickness $=0.5$ $\mathrm{mm}, \mathrm{TR}=8.0 \mathrm{~ms}, \mathrm{TE}=3.2 \mathrm{~ms}$, flip angle $=7$ degrees, $\mathrm{FOV}=256 \times 256 \times$ 190 , voxel size $=1 \times 1 \times 0.5 \mathrm{~mm}$ ) was acquired for anatomic reference and tissue classification.

A sLASER sequence (Boer et al., 2011; Arteaga de Castro et al., 2013) $(\mathrm{TR} / \mathrm{TE}=3700 / 32 \mathrm{~ms}$, bandwidth $=4 \mathrm{kHz}$, data points $=2048)$ was used in the medial ACC $\left(20 \times 20 \times 20 \mathrm{~mm}^{3}, 16\right.$ acquisitions $)$, left DLPFC (12 $\times 20 \times 20 \mathrm{~mm}^{3}, 32$ acquisitions), left hippocampus $\left(30 \times 15 \times 15 \mathrm{~mm}^{3}\right.$, 64 acquisitions), and left thalamus ( $16 \times 12 \times 16 \mathrm{~mm}^{3}, 64$ acquisitions) (Fig. 1). Because of time restrictions, only ${ }^{1} \mathrm{H}-\mathrm{MR}$ spectra from the left DLPFC, hippocampus, and thalamus were acquired as the left hemisphere is dominant in the majority of the population. VAPOR water suppression was applied (Tkác et al., 2001). A non-water-suppressed spectrum was obtained at the beginning of each sequence. Second- 

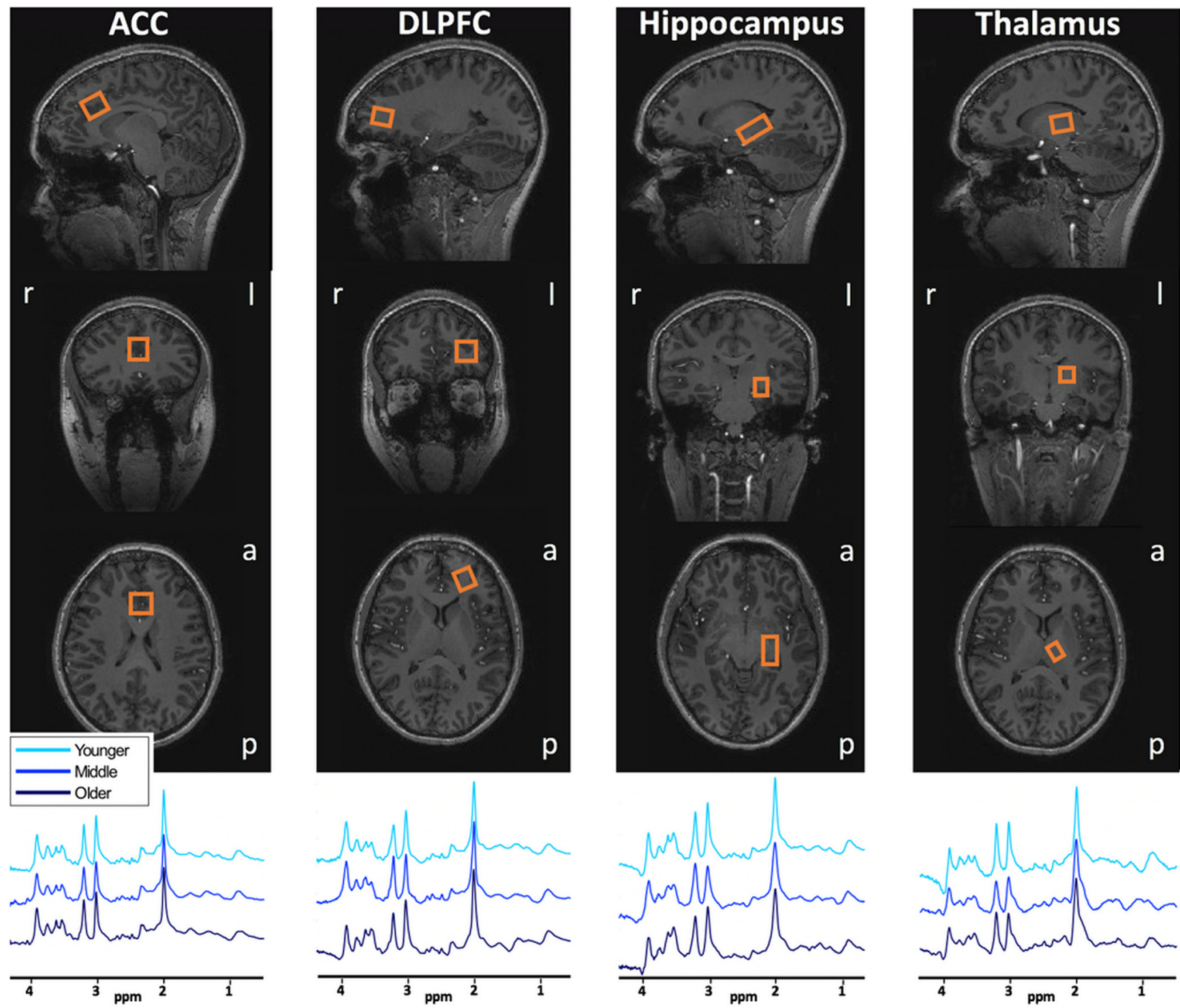

Figure 1. Voxel placements and representative spectra before processing and baseline subtraction. Orange box represents the MRS voxel. r, Right; I, left; a, anterior; $p$, posterior.

order $\mathrm{B}_{0}$ shimming was applied using the FASTMAP algorithm (Gruetter and Boesch, 1992; Gruetter, 1993) for all voxels separately using a shim box centered on the voxel and $15 \mathrm{~mm}$ longer than the voxel in each direction. Fractions of GM, WM, and CSF in each voxel were calculated with voxel-based morphometry using CAT12 (Gaser and Dahnke, 2016) implemented in SPM12 (Statistical Parametric Mapping, Wellcome Department of Cognitive Neurology) (Table 2).

\section{Spectral fitting and quantification}

Spectral quality assessment was performed based on Kreis (2004). First, visual inspection was performed, and poor-quality spectra and spectra with artifacts were excluded. After fitting with LCModel, spectra were excluded if line width (FWHM) exceeded $0.1 \mathrm{ppm}$. Metabolite values with a Cramèr-Rao lower bound (CRLB) of $\geq 20$ were excluded from the analyses (for exploratory analyses, other CRLB criteria were used; see section Exploratory metabolite analysis).

After visual inspection, 9 of 236 spectra were excluded from the analyses because of poor quality and/or artifacts: one from ACC (younger), three from DLPFC (one younger, two older), two from hippocampus (one younger, one older), and three from thalamus (one younger, one middle, one older). The remaining spectra were fitted with LCModel (Provencher, 2001) using a custom basis set with 20 metabolites (alanine,
Table 2. Voxel tissue fractions ${ }^{\mathrm{a}}$

\begin{tabular}{lccc}
\hline Variable & Younger & Middle & Older \\
\hline ACC CSF \% & $11.9 \pm 2.90^{*}$ & $14.6 \pm 6.13^{*}$ & $25.4 \pm 7.45^{* *}$ \\
ACC GM/WM & $2.76 \pm 0.55^{*}$ & $2.29 \pm 0.47^{*}$ & $2.51 \pm 0.49$ \\
DLPFC CSF \% & $4.26 \pm 1.73^{*}$ & $4.18 \pm 2.86^{*}$ & $7.78 \pm 3.73^{* *}$ \\
DLPFC GM/WM & $0.44 \pm 0.13$ & $0.41 \pm 0.13$ & $0.50 \pm 0.14$ \\
Hippocampus CSF \% & $4.23 \pm 1.60^{*}$ & $6.61 \pm 5.76^{*}$ & $12.5 \pm 4.35^{* *}$ \\
Hippocampus GM/WM & $1.11 \pm 0.17$ & $1.02 \pm 0.23$ & $1.11 \pm 0.11$ \\
Thalamus CSF \% & $<0.00 \pm<0.00$ & $<0.00 \pm<0.00$ & $<0.00 \pm<0.00$ \\
Thalamus GM/WM & $2.06 \pm 0.86^{*}$ & $1.74 \pm 0.79^{*}$ & $1.13 \pm 0.45^{* *}$ \\
\hline
\end{tabular}

${ }^{a}$ Data are mean $\pm S D$.

Age groups that are pairwise significantly different $(p<0.05)$ : *different from one other group; ${ }^{* *}$ different from both other groups. For CSF fraction in thalamus, the concentrations were too low to perform statistical tests.

ascorbate, aspartate, creatine, GABA, glutamine [Gln], Glu, glycine, glycerophosphocholine, glutathione, mIns, lactate $[\mathrm{Lac}], \mathrm{N}$-acetylaspartate [NAA], N-acetylaspartylglutamate [NAAG], phosphorylcholine, phosphocreatine, phosphorylethanolamine, scyllo-inositol [sIns], serine [Ser], and taurine [Tau]), including an in vivo measured macromolecular baseline (van de Bank et al., 2015). Levels of mIns, tCr (creatine + phosphocreatine), tCho (glycerophosphocholine + phosphorylcholine), tNAA 
Table 3. Quality variables for the ${ }^{1} \mathrm{H}-\mathrm{MRS}$ measurements ${ }^{\mathrm{a}}$

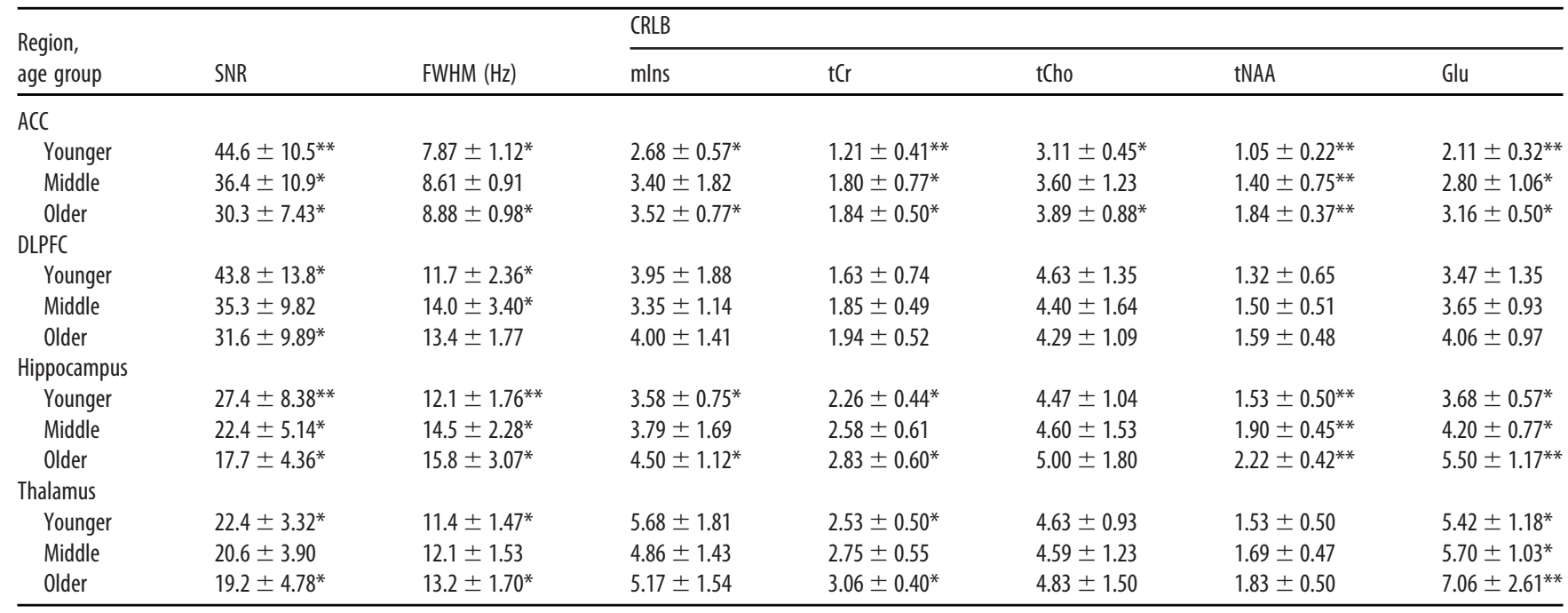

${ }^{a}$ Data are mean \pm SD. SNR, Signal-to-noise ratio.

Age groups that are pairwise significantly different $(p<0.05)$ : *different from one other group; ${ }^{* *}$ different from both other groups.

$(\mathrm{NAA}+\mathrm{NAAG})$, and Glu were used for the main analyses. The spectra were fitted between 0.2 and $4 \mathrm{ppm}$ with a knot spacing of 0.2 . Spectral quality measures were calculated for all spectra, including CRLB, FWHM, and signal-to-noise ratios (SNR). Spectral quality data are summarized in Table 3. There were no spectra with FWHM exceeding $0.1 \mathrm{ppm}$ and no metabolite values with a CRLB of $\geq 20$. Typical spectral fitting with LCModel is shown in Figure 2.

Metabolite quantification was performed through water referencing. Metabolite levels were corrected for tissue fractions in the voxel (Gasparovic et al., 2009; Quadrelli et al., 2016), including tissue-specific attenuation factors for $\mathrm{T}_{1}$ (Rooney et al., 2007) and $\mathrm{T}_{2}$ (Bartha et al., 2002) relaxation times by correcting the water concentration in the voxel (WaterConc corr $_{\text {) }}$ as follows:

$$
\begin{gathered}
\text { WaterConc }_{\text {corr }}= \\
\frac{[H 2 O] *\left(f_{G M} * R_{H 20, G M}+f_{W M} * R_{H 2 O, W M}+f_{C S F} * R_{H 2 O, C S F}\right)}{1-f_{C S F}}
\end{gathered}
$$

where the water fraction in tissue $\mathrm{x}, f_{X}$, is as follows:

$$
f_{x}=\frac{f_{x, v o l} * \operatorname{con}_{x}}{f_{G M, v o l} * \operatorname{con}_{G M}+f_{W M, v o l} * \operatorname{con}_{W M}+f_{C S F, v o l} * \operatorname{con}_{C S F}}
$$

and the tissue specific attenuation factors $R_{H 2 O . X}$ is as follows:

$$
R_{H 2 O, X}=e^{-\frac{T E}{T 2 x}} *\left(1-e^{-\frac{T R}{T 1 x}}\right)
$$

where $[\mathrm{H} 2 \mathrm{O}]$ is the concentration of pure water, $f_{x, v o l}$ is the fractional volume of tissue $\mathrm{x}$ within the voxel, $\operatorname{con}_{x}$ is the water content in tissue $\mathrm{x}$ as a fraction of pure water, and $T 1_{x}$ and $T 2_{x}$ are the $T_{1}$ and $T_{2}$ relaxation times of water in tissue $\mathrm{x}$. $\mathrm{Con}_{\mathrm{x}}$ was assumed 0.97 in CSF (Ernst et al., 1993), 0.80 in GM and 0.71 in WM (Abbas et al., 2014). The $T_{1}$ relaxation time was assumed $4425 \mathrm{~ms}$ in CSF, $2130 \mathrm{~ms}$ in GM, and $1220 \mathrm{~ms}$ in WM (Rooney et al., 2007). The $\mathrm{T}_{2}$ relaxation time was assumed $141 \mathrm{~ms}$ in CSF, $50 \mathrm{~ms}$ in GM, and $55 \mathrm{~ms}$ in WM (Bartha et al., 2002).

\section{Cognitive tests}

Cognitive testing was performed on a tablet using a custom-composed CANTAB (Cambridge Cognition) (Sahakian and Owen, 1992). For the present study, two tasks targeting vsWM were included: the paired associates learning (PAL) and the spatial working memory (SWM) task. Both tasks have been shown to be reliable and sensitive to age-related cognitive decline (Robbins et al., 1994; Gonçalves et al., 2016).
$P A L$. In PAL, boxes were displayed in a circle. The boxes were opened and closed one by one in a randomized order. Some boxes had a pattern hidden inside. Next, the patterns were displayed one by one in the middle of the screen, and the participant had to click the box where the same pattern had previously been displayed. If the correct box for one or more patterns was not chosen, the task was repeated. The number of times a participant selected the wrong box was used as outcome score. Participants had to place all patterns correctly in maximally four attempts to reach the next level with a higher number of patterns. The levels were four, six, or eight patterns. If a participant did not reach all levels, the score was adjusted for the levels not reached.

SWM. In SWM, boxes were displayed in an asymmetrical pattern. The participant had to find a hidden token in as few clicks as possible by opening the boxes one by one. When the token was found, a new token was hidden in one of the other boxes. The outcome score was the number of times a participant selected a box in which a token had previously been found. When tokens had been found in all boxes, the next level was reached. The levels were four, six, or eight boxes.

The PAL and SWM scores were correlated $(\rho=0.478, p<0.001)$. They were, therefore, $z$-scored and summed into a vsWM composite score. The vsWM score was inverted so that a higher score represented better performance.

Experimental design and statistical analysis

To minimize data loss, spectra that were excluded based on poor quality were not considered missing values. Instead, for each metabolite, the group mean in that region was imputed. Outliers were defined as metabolite levels $>3$ SDs from the group mean in a given brain region. Outlier detection led to exclusion of one hippocampal $\mathrm{tCr}$ and one thalamus mIns value, both from participants in the middle group. Outliers were excluded from further analyses and not imputed by group means.

SPSS 25 was used for statistical analyses. Threshold of significance was set to $p<0.05$, after correction for multiple comparisons where applicable. One-way ANOVA testing for the effect of age group followed by post hoc pairwise comparisons was applied to compare continuous demographic variables, spectral quality measures, tissue distributions, and scores from cognitive testing.

Overall age-related metabolite differences. A multivariate ANCOVA using Pillai's trace with mIns, tCr, tCho, tNAA, and Glu levels as dependent variables was performed to test the primary hypothesis that metabolite levels overall differed across age groups and that there was an interaction between age group and brain region. GM/WM ratio for each voxel was added as covariate.

Age-related metabolite differences. Next, to investigate the brain region-specific differences across age groups, a multivariate ANCOVA 

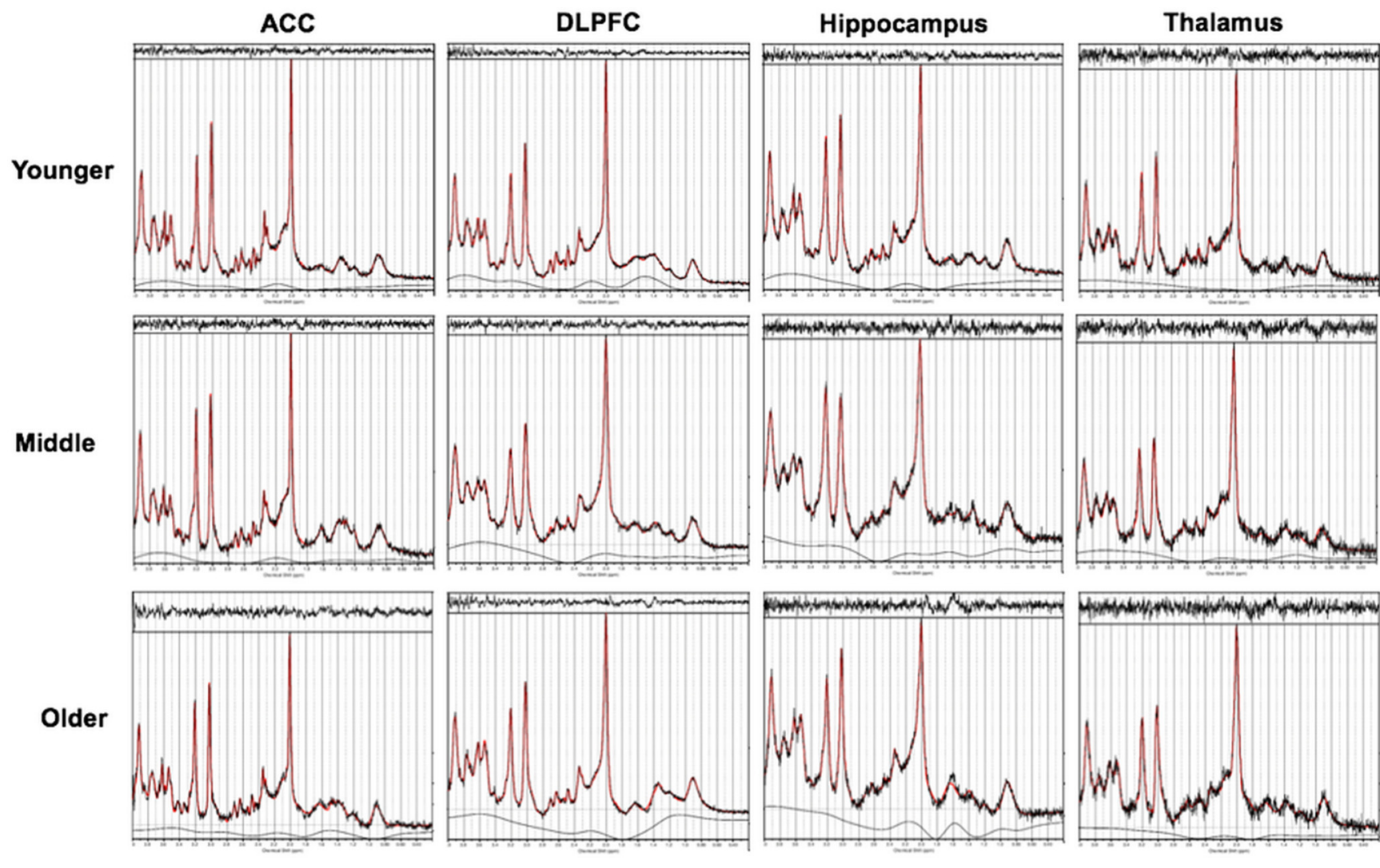

Figure 2. Typical spectral fitting with LCModel.

using Pillai's trace for each brain region separately was performed, including mIns, $\mathrm{tCr}$, tCho, tNAA, and Glu levels as dependent variables. GM/WM ratio in each voxel was added as covariate. Significant main effects were further qualified by post hoc ANCOVA and Bonferroni-corrected pairwise comparisons.

Metabolite correlations with cognition. The secondary hypothesis that age-related differences in metabolites were associated with differences in vsWM was investigated with Bonferroni-corrected (11 comparisons) partial Pearson's correlations with GM/WM ratio as covariate. Correlations were tested between vsWM score and metabolites that differed across age groups within a brain region. The tests were one-tailed, testing for a negative correlation between vsWM score and mIns, tCr, and tCho levels and a positive correlation between vsWM score and tNAA and Glu levels.

Exploratory metabolite analysis. Several metabolites not included in the main hypotheses were also acquired with ${ }^{1} \mathrm{H}$-MRS. Exploratory statistical analyses of age-related differences for these metabolites were performed per brain region with ANCOVA controlling for GM/WM ratio followed by pairwise comparisons. These exploratory analyses were not Bonferroni-corrected. CRLBs were used to filter out meaningless metabolite level estimates in an approach based on Tkác et al. (2009). First, all metabolite levels with a CRLB higher than $100 \%$ were excluded. Metabolite level estimates were only included in the analysis if $>50 \%$ of the estimates in a specific age group and brain region remained and if the average CRLB for each group was $<50 \%$.

\section{Results}

\section{tCho levels}

There was a main effect of age group for tCho in ACC, DLPFC, and hippocampus. In ACC, tCho levels were higher in the older than the younger group $(p<0.001)$ and in the middle than the younger group $(p=0.033)$. In hippocampus, tCho levels were higher in the older than the younger group $(p<0.001)$ and the older than the middle group $(p=0.010)$.

\section{Overall age-related metabolite differences}

When including all metabolites in all brain regions, there was a main effect of age group $\left(F_{(10,436)}=12.49, p<0.001\right)$ and an age group $\times$ brain region interaction $\left(F_{(30,1105)}=1.87, p=0.003\right)$. Thus, metabolite levels differ across age groups in a brain regiondependent way, and each brain region was therefore next studied separately.

\section{Age-related metabolite differences}

There was a main effect of age group in all separate brain regions, $\operatorname{ACC}\left(F_{(10,104)}=4.06, p<0.001\right)$, DLPFC $\left(F_{(10,104)}=\right.$ $4.20, p<0.001)$, hippocampus $\left(F_{(10,102)}=6.75, p<0.001\right)$, and thalamus $\left(F_{(10,102)}=2.35, p=0.015\right)$. These differences are further qualified with post hoc testing for each metabolite below. See Table 4 for metabolite levels and statistics and Figure 3 for visualization.

\section{mIns levels}

There was a main effect of age group for mIns in all brain regions. In DLPFC, mIns levels were higher in the middle than the younger group $(p<0.001)$. In hippocampus, mIns levels were higher in the older than the younger group $(p<0.001)$, in the older than the middle group $(p=0.002)$, and in the middle than the younger group $(p=0.028)$. In thalamus, mIns levels were higher in the older than the younger group $(p=0.010)$.

\section{tCr levels}

There was a main effect of age group for tCr in ACC and hippocampus. In ACC, tCr levels were higher in the older than the younger group $(p=0.005)$ and the older than the middle group $(p=0.037)$. In hippocampus, tCr levels were higher in the older 
Table 4. Brain region-specific analysis testing for effect of age group ${ }^{a}$

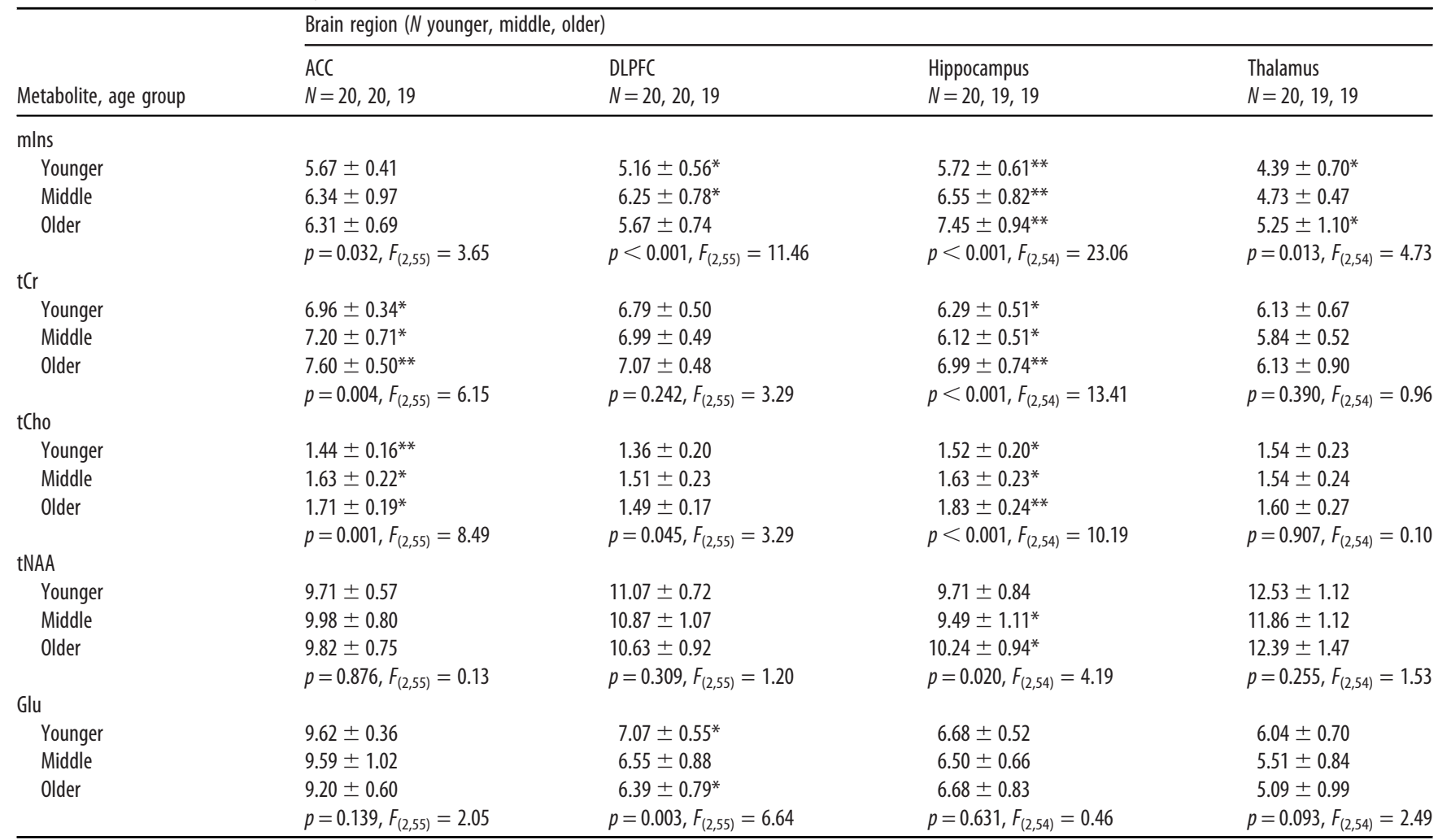

${ }^{a}$ Data are mean \pm SD.

Age groups that are pairwise significantly different $(p<0.05)$ : ${ }^{*}$ different from one other group; ${ }^{* *}$ different from both other groups.

than the younger group $(p<0.001)$ and the older than the middle group $(p<0.001)$.

\section{tNAA levels}

There was a main effect of age group for tNAA in hippocampus. In the hippocampus, the tNAA levels were higher in the older than the middle group $(p=0.018)$.

\section{Glu levels}

There was a main effect of age group for Glu in DLPFC. In DLPFC, Glu levels were lower in the older than the younger group $(p=0.002)$.

All analyses were also performed controlling for sex; this did not change the significance of the results. Registering excluded poor-quality spectra as missing values rather than imputing them with group means did not change the significance of the results, except for tCho levels in DLPFC, which were no longer different across groups.

\section{Metabolite correlations with cognitive ageing}

The vsWM, PAL, and SWM scores all differed across age groups (for statistics, see Table 5). vsWM score correlated negatively with mIns in the hippocampus $(\rho=-0.471, p=0.001)$ and thalamus $(\rho=-0.355, p=0.037)$ and with $\operatorname{tCr}(\rho=-0.364$, $p=0.027)$ and tCho $(\rho=-0.486, p<0.001)$ in the ACC (for plots, see Fig. 4). These findings remained when inserting missing values instead of imputed data. Before Bonferroni correction, significant correlations were also observed for mIns in ACC $(\rho=-0.244, p$ uncorrected $=0.032), \mathrm{tCr}$ in hippocampus $(\rho=$ -0.263 , $p$ uncorrected $=0.0424)$, and Glu in DLPFC $(\rho=0.269$, $p$ uncorrected $=0.021$ ).

\section{Exploratory metabolite analysis}

Gln, glutathione, NAA, NAAG, sIns, and Tau could be included in the analysis within the defined limits in all regions. Additionally, aspartate and GABA could be quantified in ACC, DLPFC, and thalamus and Lac and Ser could be quantified in ACC, DLPFC, and hippocampus. The exploratory analysis revealed a main effect of age group in the ACC for Lac, in the DLPFC for NAA, and in the hippocampus for Gln, NAAG, sIns, Ser, and Tau. Except for NAA, levels were higher in older age groups for all metabolites. See Table 6 for metabolite levels and statistics.

\section{Discussion}

Using 7T ${ }^{1} \mathrm{H}$-MRS, we found differences across age groups in mIns levels in DLPFC, hippocampus, and thalamus, and $\mathrm{tCr}$ and tCho levels in ACC and hippocampus with the most common difference being higher levels in the older than the younger group. Additionally, mIns levels in hippocampus and thalamus and $\mathrm{tCr}$ and tCho levels in ACC correlated negatively with cognitive ageing as reflected by vsWM performance. Levels of tNAA in hippocampus were higher in the older than the middle group, and Glu levels in DLPFC were lower in the older than the younger group. No correlations between tNAA or Glu and vsWM performance were observed.

\section{mIns, tCr, tCho, and cognitive ageing}

As hypothesized, regional levels of mIns, $\mathrm{tCr}$, and tCho were generally higher in older age groups in the ACC and hippocampus. This corresponds with some previous studies (Chang et al., 1996; Sporn et al., 2019), although other studies observed unaltered levels (Hädel et al., 2013; Ding et al., 
ACC

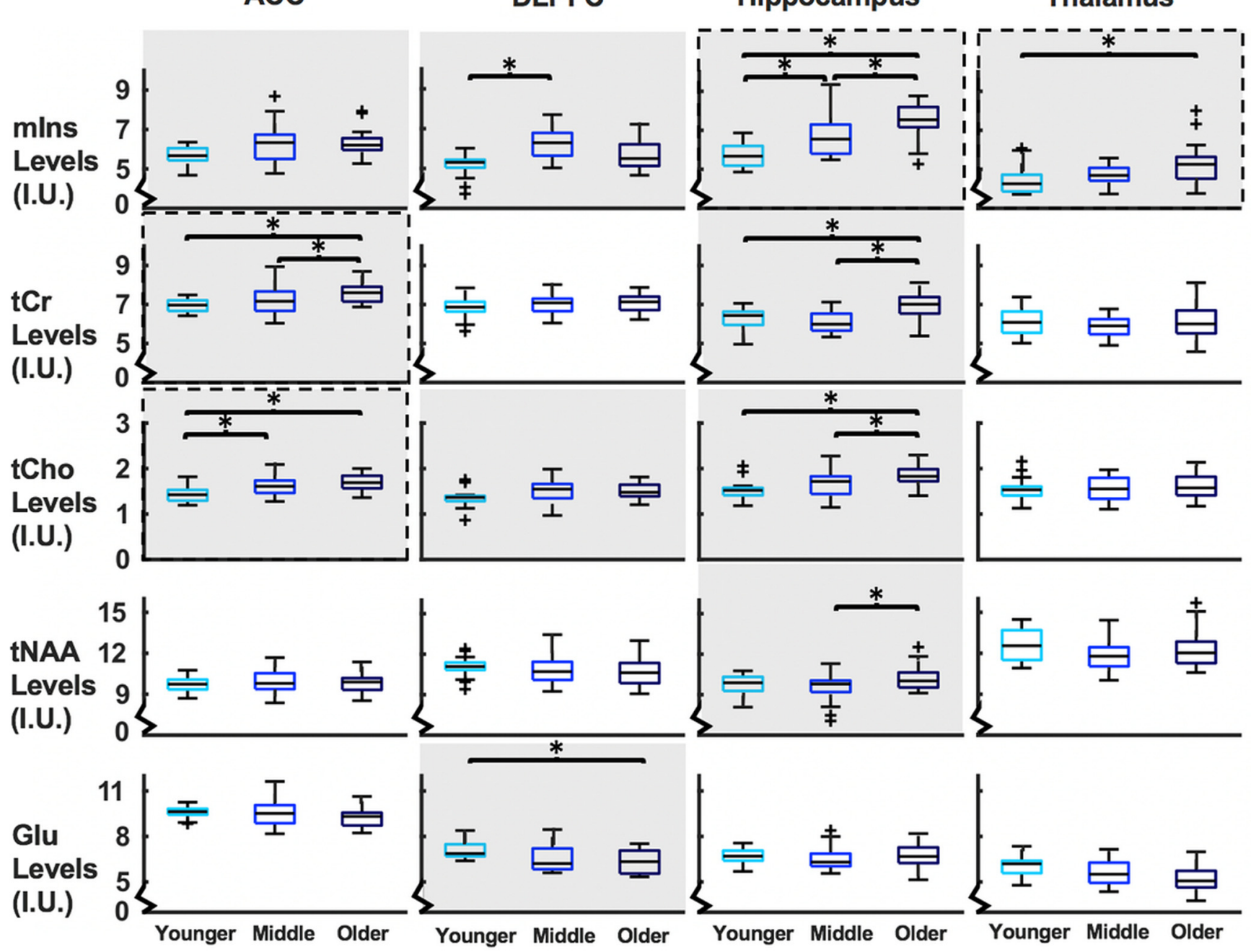

Figure 3. Boxplots of metabolite levels ( $y$ axes) separated by region and age group ( $x$ axes). Metabolites with a significant main effect of age group at ANCOVA level have a gray background. *Significant pairwise differences between groups. Metabolites that significantly correlate with vsWM score are enclosed in a dashed line. I.U., Institutional units.

Table 5. Cognitive scores ${ }^{a}$

\begin{tabular}{lcccc}
\hline Variable & Younger & Middle & \multicolumn{1}{c}{ Older } & Significance test \\
\hline vSWM score & $1.30 \pm 0.15^{* *}$ & $0.43 \pm 0.24^{* *}$ & $-1.81 \pm 0.39^{* *}$ & $p<0.001, F_{(2,56)}=33.80$ \\
PAL errors & $4.75 \pm 0.91^{*}$ & $12.0 \pm 2.15^{*}$ & $29.6 \pm 3.93^{* *}$ & $p<0.001, F_{(2,56)}=24.20$ \\
SWM errors & $3.20 \pm 0.98^{*}$ & $6.65 \pm 1.48^{*}$ & $16.1 \pm 2.03^{* *}$ & $p<0.001, F_{(2,56)}=18.41$ \\
\hline
\end{tabular}

${ }^{a}$ Data are mean $\pm S D$.

Age groups that are pairwise significantly different $(p<0.05)$ : *different from one other group; **different from both other groups.

2016). Some of the previous negative findings could, however, have arisen from not including participants older than 70 years, low field strengths, the selected scan parameters, or insufficient correction for tissue fractions (Cleeland et al., 2019; Sporn et al., 2019). In the DLPFC, levels of mIns, tCr, and tCho were not higher in the older than the younger group. As the DLPFC voxel contained more WM than GM, this corresponds with a previous study showing that changes in prefrontal mIns, creatine, and Cho levels during ageing are primarily related to GM (Chang et al., 1996). Overall, the findings of differences in mIns, tCr, and tCho across age groups in ACC and hippocampus are consistent with the common notion that these regions are especially sensitive to ageing (Hedden and Gabrieli, 2004).
Thalamus also had higher mIns levels in the older than the younger group. This has not been observed before; however, very few ${ }^{1} \mathrm{H}$-MRS ageing studies have included the thalamus. To our knowledge, this is the first ${ }^{1} \mathrm{H}$-MRS study of normal ageing in thalamus at $7 \mathrm{~T}$ and the first to include an age group $>70$ years. Accordingly, other MR techniques suggest that the thalamus may be a central node in ageing and could thus be of special interest in future ageing studies (Sullivan et al., 2004; Goldstone et al., 2018). Overall, the results indicate that levels of glia-related metabolites are elevated during ageing in ACC, hippocampus, and thalamus.vsWM was negatively correlated with tCho and tCr in ACC and mIns in hippocampus and thalamus. This study is the first to show these correlations during normal ageing; however, only few studies of metabolites and cognitive ageing exist (for review, see Cleeland et al., 2019). In PFC, the studies have mainly focused on WM (Ross et al., 2005, 2006; Kochunov et al., 2010). In hippocampus, an association between tNAA/tCr and vsWM has been observed; however, the ratio complicates interpretation (Driscoll et al., 2003). None of the studies included thalamus; however, our results correspond to findings from other types of MR studies suggesting that neurobiological ageing effects on thalamus could be a critical part of cognitive ageing (Grieve et al., 2007; Goldstone et al., 2018). 

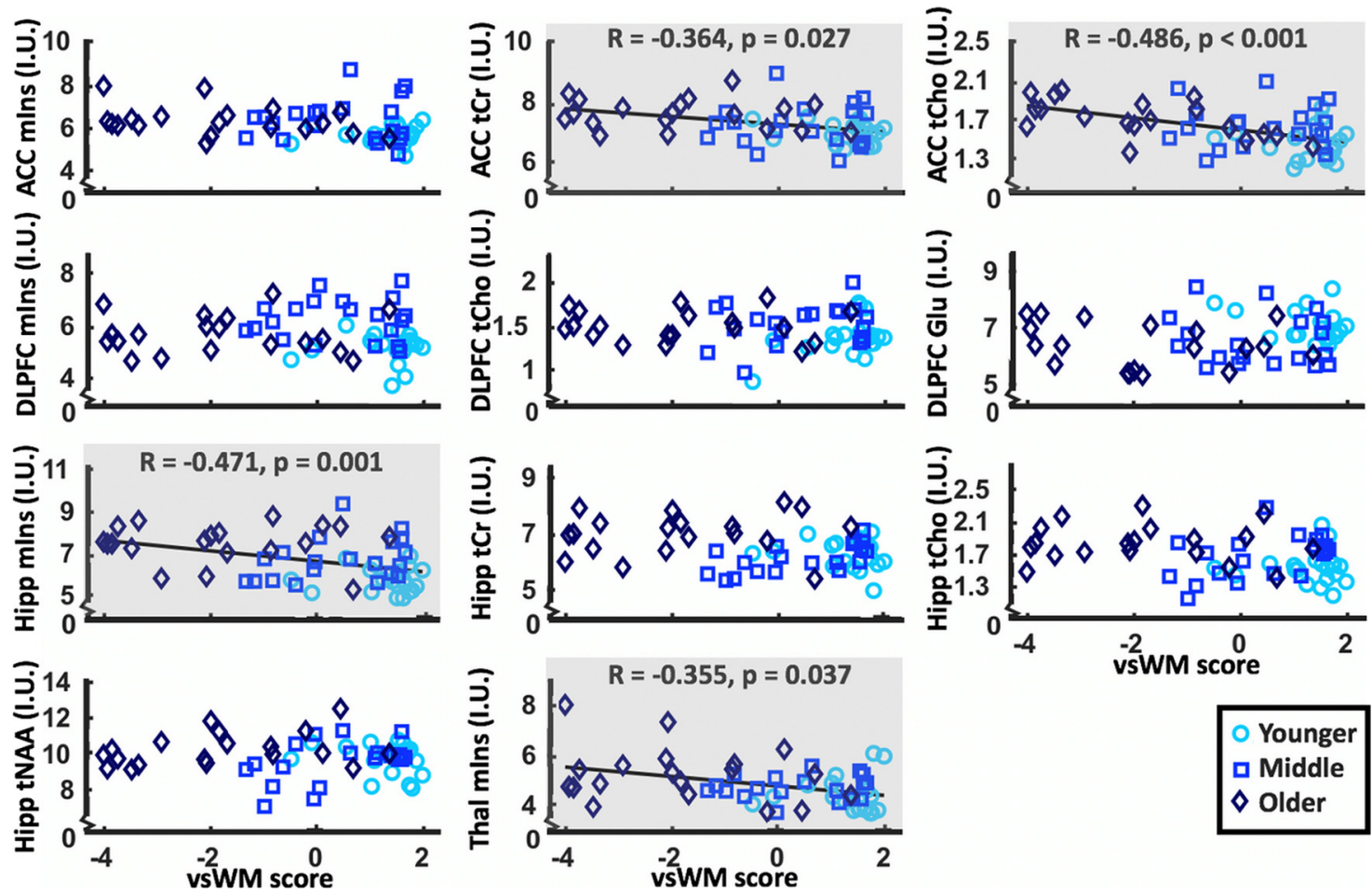

O Younger

$\square$ Middle

$\diamond$ Older

Figure 4. Scatterplots of metabolite levels that differ between age groups ( $y$ axes) and vsWM score ( $x$ axes). Gray background represents significant correlations after Bonferroni correction between metabolite levels and vsWM score. Hipp, Hippocampal; I.U., institutional units; Thal, thalamic.

Table 6. Exploratory analysis testing for effect of age group ${ }^{a}$

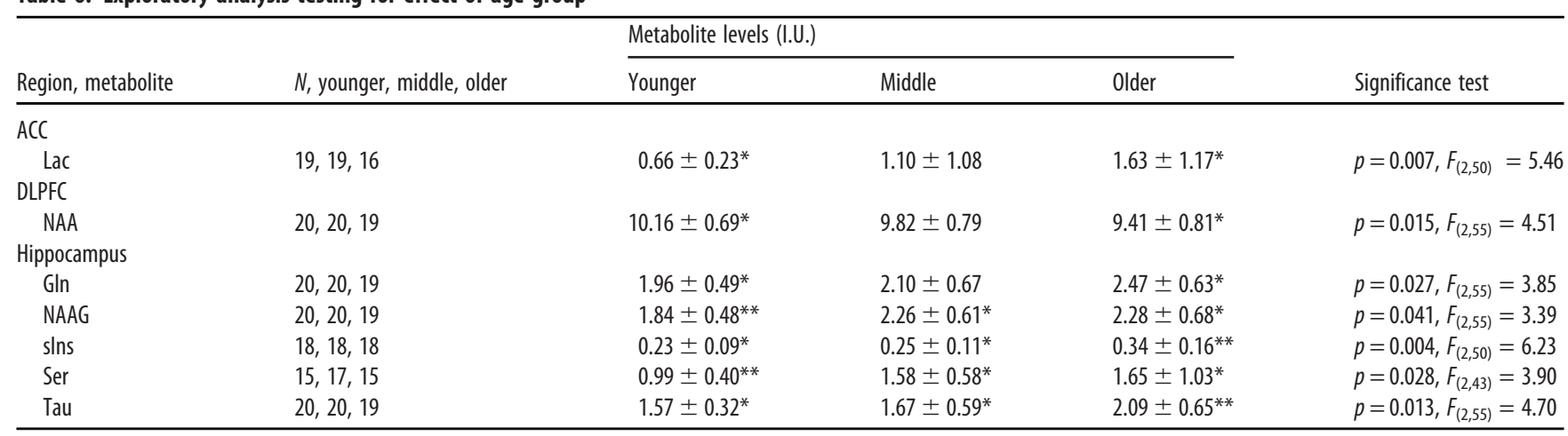

${ }^{a}$ Data are mean \pm SD. I.U., Institutional units.

Age groups that are pairwise significantly different $(p<0.05)$ : *different from one other group; ${ }^{* *}$ different from both other groups. Only significant findings are reported.

Although mIns, $\mathrm{tCr}$, and tCho can be found in both glial cells and neurons, their concentrations are significantly higher in glial cells than neurons, and an increase in their concentrations therefore potentially reflects gliosis and neuroinflammation (Glanville et al., 1989; Urenjak et al., 1993). Moreover, a concomitant increase in mIns and tCho indicates glial proliferation (Bitsch et al., 1999). This is consistent with stereological findings that the number of glial cells increase with age in the frontal and temporal cortex (Terry et al., 1987). With age, glial cells, including astrocytes and microglia, change phenotype into a more proinflammatory state (Perry et al., 2007; Cohen and Torres, 2019). This increase in neuroinflammation may negatively impact cognitive function (Sartori et al., 2012). As elevations in mIns, tCho, and $\mathrm{tCr}$ are associated with neuroinflammation, this could be the underlying mechanism for the relationship between age group, metabolites, and cognitive ageing (Chang et al., 2013). Additionally, ageing could specifically impact the synthesis and breakdown of mIns, tCr, and tCho. This would imply that ageing is associated with imbalances in cell signaling, energy homeostasis, and membrane turnover, respectively (Chang et al., 1996, 2013; Rae, 2014).

In summary, our study is the first to indicate a possible relationship between cognitive ageing of vsWM and higher levels of glia-related ${ }^{1} \mathrm{H}$-MRS metabolites in ACC, hippocampus, and thalamus. Overall, these results add to the literature, suggesting a central role for glial cells in normal cognitive ageing potentially via neuroinflammation.

\section{NAA and Glu}

Contrary to mIns, tCr, and tCho, tNAA and Glu are both commonly regarded to reflect neuronal health and function, suggesting that the often observed decrease in their levels is linked to compromised neuronal integrity (Clark, 1998; Demougeot et al., 2001; Rae, 2014). In this study, regional levels of tNAA 
and Glu were not lower in older age groups, except for Glu levels in DLPFC. This corresponds to some studies (Harada et al., 2001; Chang et al., 2009; Haga et al., 2009; Reyngoudt et al., 2012), whereas other studies report lower levels with age (Brooks et al., 2001; Schubert et al., 2004; Ding et al., 2016). Studies reporting lower levels have, however, often quantified the metabolite by calculating the ratio to $\mathrm{tCr}$, which could just as well reflect higher tCr levels (Haga et al., 2009). The lower levels of Glu observed only in the DLPFC in this study could suggest that neuronal health or function is altered in this region. That tNAA remains unaltered in PFC during normal ageing is consistent with stereological observations that frontal neuronal density does not decline with age (Terry et al., 1987). In hippocampus, tNAA levels were even higher rather than lower between the middle and the older group. When previously observed, higher tNAA levels with older age were proposed to arise from the hippocampal neurons' retained ability for growth in later life and might thus represent a beneficial effect (Lie et al., 2004; Bettio et al., 2017; Sporn et al., 2019). On the contrary, lower tNAA levels have been associated with age-related neurodegenerative diseases (Kantarci et al., 2013). Inadvertent recruitment of participants in preclinical stages of disease in studies of normal ageing could thus have resulted in an apparent tNAA decrease with age. Lower tNAA might thus be a trait of pathologic rather than normal ageing (Harada et al., 2001; Murray et al., 2014; Wang et al., 2015).

In our exploratory analysis, we used the increased spectral resolution of $7 \mathrm{~T}{ }^{1} \mathrm{H}$-MRS to distinguish between NAA and NAAG. Our exploratory analysis indicated that NAA levels were lower in older age groups in DLPFC, which was not the case for tNAA. In hippocampus, the results suggest that the higher tNAA levels in the older than middle group could arise from higher NAAG rather than higher NAA. NAAG is a derivative of NAA which might be involved in neuron to glia signaling (Baslow, 2000). It has previously been observed to be associated with ageing in parietal and occipital cortex (Marjańska et al., 2017). The results in this study were only exploratory; however, they support that there could be valuable information in separating NAA and NAAG in future ageing studies.

\section{Other metabolites}

In ACC, Lac levels were higher in the older group compared with the younger group. Together with the differences across age group in mIns and tCho levels, this further indicates neuroinflammation (Bitsch et al., 1999). In hippocampus, Gln, sIns, Ser, and Tau levels were higher in older age groups. For Gln and sIns, levels have also previously been observed to be higher with age, albeit not necessarily in the same brain regions as used in this study (Kaiser et al., 2005; Hädel et al., 2013). Together with the effect on $\mathrm{tCr}$, this could indicate age-related differences in energy metabolism (Rae, 2014). Higher levels of the amino acids Tau and Ser have, to our knowledge, not been observed before. Overall, the results suggest that several different processes are changing with age in the hippocampus. This analysis was, however, exploratory and complicated by low metabolite concentrations and overlapping ${ }^{1} \mathrm{H}-\mathrm{MRS}$ signals (Kaiser et al., 2005). Thus, more studies are needed to clarify the association between these metabolites and ageing.

\section{Limitations}

The study is cross-sectional rather than longitudinal; thus, claims of causality and temporal dynamics (i.e., true decline in metabolites or cognitive performance) cannot be made. Participant recruitment was based on participants responding to an advertisement, which might have caused a recruitment bias. Further, only one cognitive domain was used to exemplify cognitive ageing and correlations might thus be specific for vsWM function rather than relating to cognitive ageing in general. Last, participants underwent cognitive testing while in a fasting state, which could have affected cognitive functioning (Galioto and Spitznagel, 2016).

Regarding ${ }^{1} \mathrm{H}-\mathrm{MRS}$, age and tissue type may affect $\mathrm{T}_{2}$ relaxation time constants of metabolites differently; however, these attenuation factors are unknown for 7T (Kirov et al., 2008). In relation to tissue type, the setup of the ${ }^{1} \mathrm{H}$-MRS voxel allowed us to control for tissue type across participants but not for distinguishing whether metabolite differences related specifically to one tissue type. The same macromolecular baseline was applied for all age groups and brain regions. Macromolecular content may change across age groups and brain regions (Marjańska et al., 2018); however, the effect of this on measured metabolite levels is not clear. Furthermore, the quality of the ${ }^{1} \mathrm{H}-\mathrm{MRS}$ spectra was generally better for the younger than the older group.

Because of time restrictions, only ${ }^{1} \mathrm{H}-\mathrm{MR}$ spectra from the left DLPFC, hippocampus, and thalamus were acquired. vsWM has been suggested to be primarily a right lateralized function (Smith and Jonides, 1997); however, recent evidence shows that vsWM is probably supported by both the right and the left hemisphere (Paulraj et al., 2018). Moreover, lateralization of spatial WM function may change in older populations (Reuter-Lorenz et al., 2000).

In conclusion, this study provides $7 \mathrm{~T}{ }^{1} \mathrm{H}-\mathrm{MRS}$ evidence that, in ACC, hippocampus, and thalamus, older age groups have higher levels of the glia-related metabolites $\mathrm{mIns}, \mathrm{tCr}$, and tCho, scaling negatively with vsWM performance. These findings emphasize the role for glial cells across multiple brain regions in normal cognitive ageing and suggest that $7 \mathrm{~T}{ }^{1} \mathrm{H}$-MRS measurements of glia-related metabolites in key regions of normal brain ageing might be useful in future studies. We have thus identified a set of $7 \mathrm{~T}^{1} \mathrm{H}$-MRS biomarkers that may help describe cognitive ageing. Understanding normal cognitive ageing is a vital step toward identifying the distinguishing features of successful and pathologic ageing.

\section{References}

Abbas Z, Gras V, Möllenhoff K, Keil F, Oros-Peusquens AM, Shah NJ (2014) Analysis of proton-density bias corrections based on T1 measurement for robust quantification of water content in the brain at 3 Tesla. Magn Reson Med 72:1735-1745.

Arteaga de Castro CS, Boer VO, Andreychenko A, Wijnen JP, van der Heide UA, Luijten PR, Klomp DW (2013) Improved efficiency on editing MRS of lactate and $\gamma$-aminobutyric acid by inclusion of frequency offset corrected inversion pulses at high fields. NMR Biomed 26:1213-1219.

Bartha R, Michaeli S, Merkle H, Adriany G, Andersen P, Chen W, Ugurbil K, Garwood M (2002) In vivo $1 \mathrm{H}_{2} \mathrm{O} \mathrm{T2}{ }^{+}$measurement in the human occipital lobe at $4 \mathrm{~T}$ and $7 \mathrm{~T}$ by Carr-Purcell MRI: detection of microscopic susceptibility contrast. Magn Reson Med 47:742-750.

Baslow MH (2000) Functions of N-acetyl-L-aspartate and N-acetyl-L-aspartylglutamate in the vertebrate brain: role in glial cell-specific signaling. J Neurochem 75:453-459.

Bettio LE, Rajendran L, Gil-Mohapel J (2017) The effects of ageing in the hippocampus and cognitive decline. Neurosci Biobehav Rev 79:66-86.

Bitsch A, Bruhn H, Vougioukas V, Stringaris A, Lassmann H, Frahm J, Brück W (1999) Inflammatory CNS demyelination: histopathologic correlation with in vivo quantitative proton MR spectroscopy. AJNR Am J Neuroradiol 20:1619-1627. 
Boer VO, van Lier A, Hoogduin JM, Wijnen JP, Luijten PR, Klomp DW (2011) 7-T ${ }^{1} \mathrm{H}$ MRS with adiabatic refocusing at short TE using radiofrequency focusing with a dual-channel volume transmit coil. NMR Biomed 24:1038-1046.

Brockmole JR, Logie RH (2013) Age-related change in visual working memory: a study of 55,753 participants aged 8-75. Front Psychol 4:1-5.

Brooks JC, Roberts N, Kemp GJ, Gosney MA, Lye M, Whitehouse GH (2001) A proton magnetic resonance spectroscopy study of age-related changes in frontal lobe metabolite concentrations. Cereb Cortex 11:598605.

Chang L, Ernst T, Poland RE, Jenden DJ (1996) In vivo proton magnetic resonance spectroscopy of the normal ageing human brain. Life Sci 58:2049-2056.

Chang L, Jiang CS, Ernst T (2009) Effects of age and sex on brain glutamate and other metabolites. Magn Reson Imaging 27:142-145.

Chang L, Munsaka SM, Kraft-Terry S, Ernst T (2013) Magnetic resonance spectroscopy to assess neuroinflammation and neuropathic pain. J Neuroimmune Pharmacol 8:576-593.

Chiu PW, Mak HK, Yau KK, Chan Q, Chang RC, Chu LW (2014) Metabolic changes in the anterior and posterior cingulate cortices of the normal ageing brain: proton magnetic resonance spectroscopy study at $3 \mathrm{~T}$. Age 36:251-264.

Cichocka M, Bereś A (2018) From fetus to older age: a review of brain metabolic changes across the lifespan. Ageing Res Rev 46:60-73.

Clark JB (1998) N-Acetyl aspartate: a marker for neuronal loss or mitochondrial dysfunction. Dev Neurosci 20:271-276.

Cleeland C, Pipingas A, Scholey A, White D (2019) Neurochemical changes in the ageing brain: a systematic review. Neurosci Biobehav Rev 98:306319.

Cohen J, Torres C (2019) Astrocyte senescence: evidence and significance. Aging Cell 18:e12937.

Demougeot C, Garnier P, Mossiat C, Bertrand N, Giroud M, Beley A, Marie C (2001) N-Acetylaspartate, a marker of both cellular dysfunction and neuronal loss: its relevance to studies of acute brain injury. J Neurochem 77:408-415.

Ding XQ, Maudsley AA, Sabati M, Sheriff S, Schmitz B, Schütze M, Bronzlik P, Kahl KG, Lanfermann H (2016) Physiological neuronal decline in healthy ageing human brain: an in vivo study with MRI and short echotime whole-brain 1H MR spectroscopic imaging. Neuroimage 137:45-51.

Driscoll I, Hamilton DA, Petropoulos H, Yeo RA, Brooks WM, Baumgartner RN, Sutherland RJ (2003) The aging hippocampus: cognitive, biochemical and structural findings. Cereb Cortex 13:1344-1351.

Ernst T, Kreis R, Ross BD (1993) Absolute quantitation of water and metabolites in the human brain: I. Compartments and water. J Magn Reson Ser B 102:1-8.

Eylers VV, Maudsley AA, Bronzlik P, Dellani PR, Lanfermann H, Ding XQ (2016) Detection of normal aging effects on human brain metabolite concentrations and microstructure with whole-brain MR spectroscopic imaging and quantitative MR imaging. AJNR Am J Neuroradiol 37:447454.

Galioto R, Spitznagel MB (2016) The effects of breakfast and breakfast composition on cognition in children and adolescents: a systematic review. Adv Nutr 7:590S-612S.

Gaser C, Dahnke R (2016) CAT-A: computational anatomy toolbox for the analysis of structural MRI data. Hum Brain Mapp 32:336-348.

Gasparovic C, Yeo R, Mannell M, Ling J, Elgie R, Phillips J, Doezema D, Mayer AR (2009) Neurometabolite concentrations in gray and white matter in mild traumatic brain injury: an ${ }^{1} \mathrm{H}$-magnetic resonance spectroscopy study. J Neurotrauma 26:1635-1643.

Glanville NT, Byers DM, Cook HW, Spence MW, Palmer FB (1989) Differences in the metabolism of inositol and phosphoinositides by cultured cells of neuronal and glial origin. Biochim Biophys Acta 1004:169179.

Goldstone A, Mayhew SD, Hale JR, Wilson RS, Bagshaw AP (2018) Thalamic functional connectivity and its association with behavioral performance in older age. Brain Behav 8:e00943.

Gonçalves MM, Pinho MS, Simões MR (2016) Test-retest reliability analysis of the Cambridge Neuropsychological Automated Tests for the assessment of dementia in older people living in retirement homes. Appl Neuropsychol Adult 23:251-263.
Grieve SM, Williams LM, Paul RH, Clark CR, Gordon E (2007) Cognitive aging, executive function, and fractional anisotropy: a diffusion tensor MR imaging study. AJNR Am J Neuroradiol 28:226-235.

Gruber S, Pinker K, Riederer F, Chmelík M, Stadlbauer A, Bittšanský M, Mlynárik V, Frey R, Serles W, Bodamer O, Moser E (2008) Metabolic changes in the normal aging brain: consistent findings from short and long echo time proton spectroscopy. Eur J Radiol 68:320-327.

Gruetter R (1993) Automatic, localized in vivo adjustment of all first-andsecond-order shim coils. Magn Reson Med 29:804-811.

Gruetter R, Boesch C (1992) Fast, noniterative shimming of spatially localized signals: in vivo analysis of the magnetic field along axes. J Magn Reson 96:323-334.

Hädel S, Wirth C, Rapp M, Gallinat J, Schubert F (2013) Effects of age and sex on the concentrations of glutamate and glutamine in the human brain. J Magn Reson Imaging 38:1480-1487.

Haga KK, Khor YP, Farrall A, Wardlaw JM (2009) A systematic review of brain metabolite changes, measured with ${ }^{1} \mathrm{H}$ magnetic resonance spectroscopy, in healthy aging. Neurobiol Aging 30:353-363.

Harada M, Miyoshi H, Otsuka H, Nishitani H, Uno M (2001) Multivariate analysis of regional metabolic differences in normal aging on localised quantitative proton MR spectroscopy. Neuroradiology 43:448-452.

Hedden T, Gabrieli JD (2004) Insights into the aging mind: a view from cognitive neuroscience. Nat Rev Neurosci 5:87-96.

Kaiser LG, Schuff N, Cashdollar N, Weiner MW (2005) Scyllo-inositol in normal aging human brain: ${ }^{1} \mathrm{H}$ magnetic resonance spectroscopy study at 4 Tesla. NMR Biomed 18:51-55.

Kantarci K, Weigand SD, Przybelski SA, Preboske GM, Pankratz VS, Vemuri P, Senjem ML, Murphy MC, Gunter JL, Machulda MM, Ivnik RJ, Roberts RO, Boeve BF, Rocca WA, Knopman DS, Petersen RC, Jack CR (2013) MRI and MRS predictors of mild cognitive impairment in a population-based sample. Neurology 81:126-133.

Kirov II, Fleysher L, Fleysher R, Patil V, Liu S, Gonen O (2008) Age dependence of regional proton metabolites $\mathrm{T} 2$ relaxation times in the human brain at 3 T. Magn Reson Med 60:790-795.

Kochunov P, Coyle T, Lancaster J, Robin DA, Hardies J, Kochunov V, Bartzokis G, Stanley J, Royall D, Schlosser AE, Null M, Fox PT (2010) Processing speed is correlated with cerebral health markers in the frontal lobes as quantified by neuroimaging. Neuroimage 49:1190-1199.

Kreis R (2004) Issues of spectral quality in clinical ${ }^{1} \mathrm{H}$-magnetic resonance spectroscopy and a gallery of artifacts. NMR Biomed 17:361-381.

Lie DC, Song H, Colamarino SA, Ming G, Gage FH (2004) Neurogenesis in adult brain: new strategies for central nervous system diseases. Annu Rev Pharmacol Toxicol 44:399-421.

Marjańska M, McCarten R, Hodges J, Hemmy LS, Grant A, Deelchand DK, Terpstra M (2017) Region-specific aging of the human brain as evidenced by neurochemical profiles measured noninvasively in the posterior cingulate cortex and the occipital lobe using ${ }^{1} \mathrm{H}$ magnetic resonance spectroscopy at 7 T. Neuroscience 354:168-177.

Marjańska M, Deelchand DK, Hodges JS, McCarten JR, Hemmy LS, Grant A, Terpstra M (2018) Altered macromolecular pattern and content in the aging human brain. NMR Biomed 31:1-8.

Murray ME, Przybelski SA, Lesnick TG, Liesinger AM, Spychalla A, Zhang B, Gunter JL, Parisi JE, Boeve BF, Knopman DS, Petersen RC, Jack CR, Dickson DW, Kantarci K (2014) Early Alzheimer's disease neuropathology detected by proton MR spectroscopy. J Neurosci 34:16247-16255.

Owen AM, Morris RG, Sahakian BJ, Polkey CE, Robbins TW (1996) Double dissociations of memory and executive functions in working memory tasks following frontal lobe excisions, temporal lobe excisions or amygdalo-hippocampectomy in man. Brain 119:1597-1615.

Paulraj SR, Schendel K, Curran B, Dronkers NF, Baldo J (2018) Role of the left hemisphere in visuospatial working memory. J Neurolinguistics 48:133-141.

Perry VH, Cunningham C, Holmes C (2007) Systemic infections and inflammation affect chronic neurodegeneration. Nat Rev Immunol 7:161-167.

Provencher SW (2001) Automatic quantitation of localized in vivo ${ }^{1} \mathrm{H}$ spectra with LCModel. NMR Biomed 14:260-264.

Quadrelli S, Mountford C, Ramadan S (2016) Hitchhiker's guide to voxel segmentation for partial volume correction of in vivo magnetic resonance spectroscopy. Magn Reson Insights 27:1-8.

Rae CD (2014) A guide to the metabolic pathways and function of metabolites observed in human brain ${ }^{1} \mathrm{H}$ magnetic resonance spectra. Neurochem Res 39:1-36. 
Reuter-Lorenz PA, Jonides J, Smith EE, Hartley A, Miller A, Marshuetz C, Koeppe RA (2000) Age differences in the frontal lateralization of verbal and spatial working memory revealed by PET. J Cogn Neurosci 12:174187.

Reyngoudt H, Claeys T, Vlerick L, Verleden S, Acou M, Deblaere K, Deene Y, De Audenaert K, Goethals I, Achten E (2012) Age-related differences in metabolites in the posterior cingulate cortex and hippocampus of normal aging brain: a ${ }^{1} \mathrm{H}-\mathrm{MRS}$ study. Eur J Radiol 81:e223-e231.

Robbins TW, James M, Owen AM, Sahakian BJ, McInnes L, Rabbitt P (1994) Cambridge Neuropsychological Test Automated Battery (CANTAB): a factor analytic study of a large sample of normal elderly volunteers. Dementia 5:266-281.

Rooney WD, Johnson G, Li X, Cohen ER, Kim SG, Ugurbil K, Springer CS (2007) Magnetic field and tissue dependencies of human brain longitudinal $1 \mathrm{H}_{2} \mathrm{O}$ relaxation in vivo. Magn Reson Med 57:308-318.

Ross AJ, Sachdev PS, Wen W, Valenzuela MJ, Brodaty H (2005) Cognitive correlates of ${ }^{1} \mathrm{H}$ MRS measures in the healthy elderly brain. Brain Res Bull 66:9-16.

Ross AJ, Sachdev PS, Wen W, Brodaty H (2006) Longitudinal changes during aging using proton magnetic resonance spectroscopy. J Gerontol A Biol Sci Med Sci 61:291-298.

Sahakian BJ, Owen AM (1992) Computerized assessment in neuropsychiatry using CANTAB: discussion paper. J R Soc Med 85:399-402.

Sartori AC, Vance DE, Slater LZ, Crowe M (2012) The impact of inflammation on cognitive function in older adults: implications for healthcare practice and research. J Neurosci Nurs 44:206-217.

Schubert F, Gallinat J, Seifert F, Rinneberg H (2004) Glutamate concentrations in human brain using single voxel proton magnetic resonance spectroscopy at 3 Tesla. Neuroimage 21:1762-1771.

Smith E, Jonides J (1997) Working memory: a view from neuroimaging. Cogn Psychol 33:5-42.
Sporn L, MacMillan EL, Ge R, Greenway K, Vila-Rodriguez F, Laule C (2019) Longer repetition time proton MR spectroscopy shows increasing hippocampal and parahippocampal metabolite concentrations with aging. J Neuroimaging: 29:592-597.

Sullivan EV, Rosenbloom M, Serventi KL, Pfefferbaum A (2004) Effects of age and sex on volumes of the thalamus, pons, and cortex. Neurobiol Aging 25:185-192.

Terpstra M, Cheong I, Lyu T, Deelchand DK, Emir UE, Bednarõík P, Eberly LE, Öz G (2016) Test-retest reproducibility of neurochemical profiles with short-echo, single-voxel MR spectroscopy at 3T and 7T. Magn Reson Med 76:1083-1091.

Terry RD, DeTeresa R, Hansen LA (1987) Neocortical cell counts in normal human adult aging. Ann Neurol 21:530-539.

Tkác I, Andersen P, Adriany G, Merkle H, Ugurbil K, Guetter R (2001) In vivo ${ }^{1} \mathrm{H}$ NMR spectroscopy of the human brain at 7T. Magn Reson Med 46:199-251.

Tkác I, Oz G, Adriany G, Ugurbil K, Gruetter R (2009) In vivo ${ }^{1} \mathrm{H}$ NMR spectroscopy of the human brain at high magnetic fields: metabolite quantification at 4T vs. 7T. Magn Reson Med 62:868-879.

Urenjak J, Williams SR, Gadian DG, Noble M (1993) Proton nuclear magnetic resonance spectroscopy unambiguously identifies different neural cell types. J Neurosci 13:981-989.

van de Bank BL, Emir UE, Boer VO, van Asten JJ, Maas MC, Wijnen JP, Kan $\mathrm{HE}, \mathrm{Oz}$ G, Klomp DW, Scheenen TW (2015) Multi-center reproducibility of neurochemical profiles in the human brain at 7 Tesla. NMR Biomed 28:306-316.

Wang H, Tan L, Wang HF, Liu Y, Yin RH, Wang WY, Chang XL, Jiang T, Yu JT (2015) Magnetic resonance spectroscopy in Alzheimer's disease: systematic review and meta-analysis. J Alzheimers Dis 46:1049-1070.

Yang ZY, Yue Q, Xing HY, Tan QY, Sun HQ, Gong QY, Tan ZJ, Quan H (2015) A quantitative analysis of $1 \mathrm{H}-\mathrm{MR}$ spectroscopy at 3.0T of three brain regions from childhood to middle age. Br J Radiol 88:1-10. 